\title{
Unilateral Spatial Neglect Due to Stroke
}

\author{
Aiko Osawa ${ }^{1}$ Shinichiro Maeshima² \\ ${ }^{1}$ Department of Rehabilitation Medicine, National Center for Geriatrics and Gerontology, \\ Aichi, Japan; ${ }^{2}$ Kinjo University, Ishikawa, Japan
}

Author for correspondence: Shinichiro Maeshima, Kinjo University, Ishikawa, Japan.

Email: shinichiromaeshima@gmail.com

Doi: https://doi.org/10.36255/exonpublications.stroke.spatialneglect.2021

\begin{abstract}
Unilateral spatial neglect refers to a condition where patients do not react to various environmental stimuli originating from the contralateral side of a brain lesion, in the absence of other sensory or motor deficits. Consequently, activities of daily living can be adversely affected. Cerebral hemorrhage or infarction is often the cause, and approximately $80 \%$ of patients with right hemisphere injury from acute stroke show unilateral spatial neglect. The presence of unilateral spatial neglect is determined through a number of different tests. However, even cases that are not apparent from typical tests are often associated with symptoms of neglect in activities of daily living. Stroke-mediated unilateral spatial neglect may improve or disappear during rehabilitation; however, in most cases, it remains. Cerebral hemorrhage, bleeding site, level of hematoma, and age are closely related with prognosis. Treatment approaches include conscious behavioral changes and activation of higher-order central nerves by stimulation from the periphery. Several mechanisms have been proposed to explain the onset of unilateral spatial neglect. Therefore, treatment strategies should be formulated only after careful examination and determination of the causative mechanism specific to each patient. This will enable the rehabilitation team to provide the most appropriate support.
\end{abstract}

Keywords: cerebral infarction; cerebral hemorrhage; stroke; rehabilitation; unilateral spatial neglect

In: Stroke. Dehkharghani S (Editor). Exon Publications, Brisbane, Australia. ISBN: 978-0-6450017-6-1; Doi: https://doi.org/10.36255/exonpublications.stroke.2021

Copyright: The Authors.

License: This open access article is licenced under Creative Commons Attribution-NonCommercial 4.0 International (CC BY-NC 4.0) https://creativecommons.org/licenses/by-nc/4.0/ 


\section{INTRODUCTION}

Unilateral spatial neglect (USN) is a contralesional space awareness disorder where patients do not react to various stimuli or conditions originating from the contralateral side of a brain lesion, even though there is no elementally impaired sensory or motor function (1). Stroke patients with USN often require careful monitoring for difficulties with daily self-care activities such as eating and dressing, due to neglect of the affected side and the risk of falls and fractures associated with transfers and walking. These factors inhibit rehabilitation, which increases the degree of dependence associated with activities of daily living (ADL). This chapter describes the evaluation, clinical condition, and treatment of USN attributed to stroke.

\section{HOW TO EXAMINE UNILATERAL SPATIAL NEGLECT}

USN is not a visual field defect such as homonymous hemianopia. Unlike homonymous hemianopia, where a fixed visual line cannot be seen on one side, USN causes the patient to overlook one side even in situations where the head and eyes are free to move (2). Even if a visual field test is performed by the confrontation procedure, one side is not completely noticed. For example, if one tries to touch the centre of a $30 \mathrm{~cm}$ cord, the right side is touched instead (Figure 1).

Behavioural observation is important in patients with USN. Space can be divided into personal space, peripersonal space, and extrapersonal space (Figure 2). Patients often neglect one side of their body, leave their beard unshaved, or forget to wear glasses. Even if a patient is sitting on a bed or in a wheelchair, he or she may face one direction for a prolonged period, or fail to notice another person in the room. Thus, the presence of USN is often associated with a neglect symptom in any of the three spaces, but may occur in the peripersonal space and not in the extrapersonal space, or vice versa (3). This condition can also be classified in terms of the spatial coordinate axis. In other words, it is classified as egocentric neglect when one neglects all information from one side, and allocentric neglect when one side of an object is neglected. In the former case, the patient does not notice an object in one hemisphere and neglects that side entirely, whereas in the latter case, the patient does not notice one side of the object and neglects that side of the object (4).

USN is thought to present in approximately $40 \%$ of cases with right hemisphere injury (5-11). Reports show that approximately $80 \%$ of patients with right hemisphere injury from acute stroke display USN $(12-15)$. This variation may be due to differences in the underlying cause of the lesions, time from the onset, and evaluation methods (Table 1). In any case, it is important to consider the possibility of accompanied USN when examining patients with right cerebral hemisphere injury.

\section{ASSESSMENT FOR UNILATERAL SPATIAL NEGLECT}

Once the patient is in a sitting position, an examination is performed at the desk. The line bisection test, cancellation test, and figure copying are common tests, but 


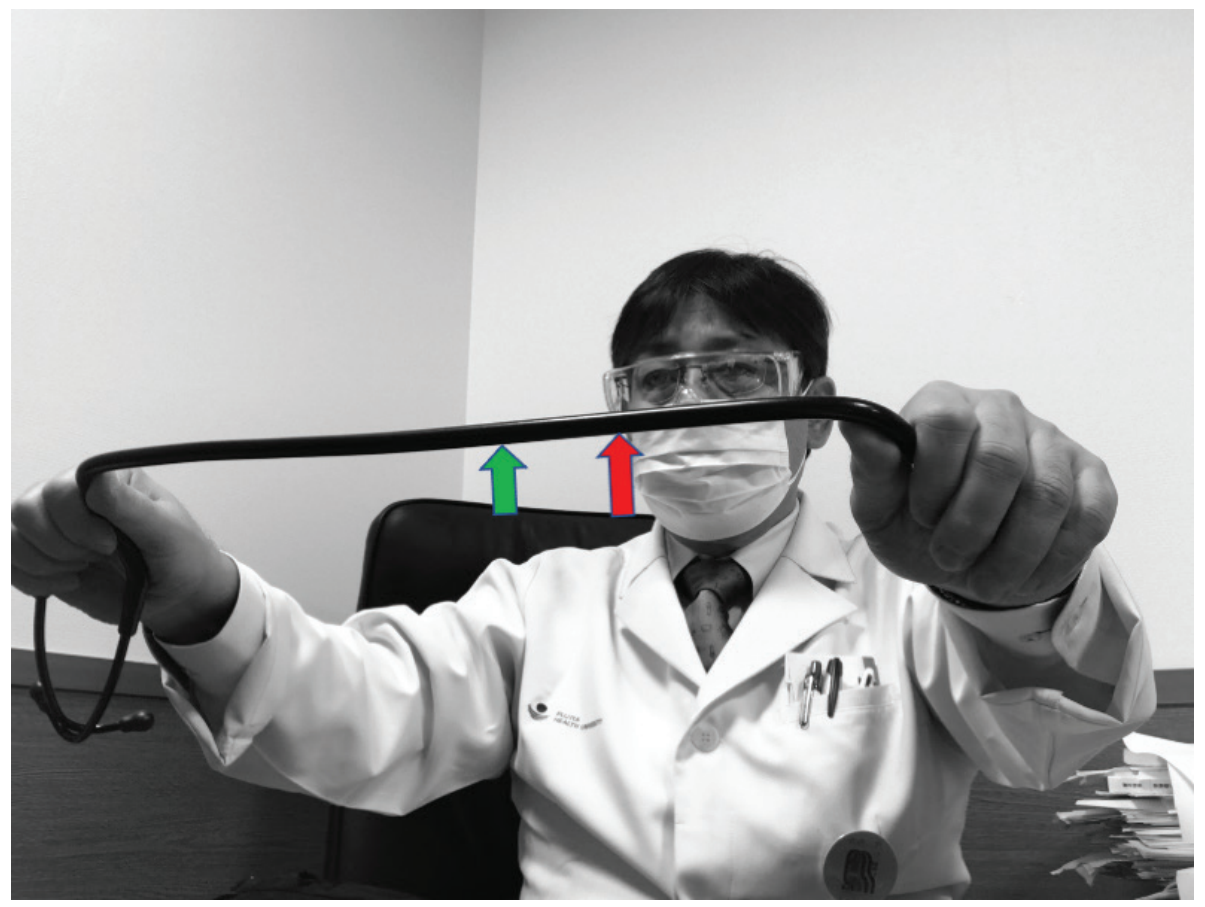

Figure 1. When the physician asks the patient with unilateral spatial neglect to point to the middle of the stethoscope, the patient point to the right side (red arrow) rather than the middle (green arrow).

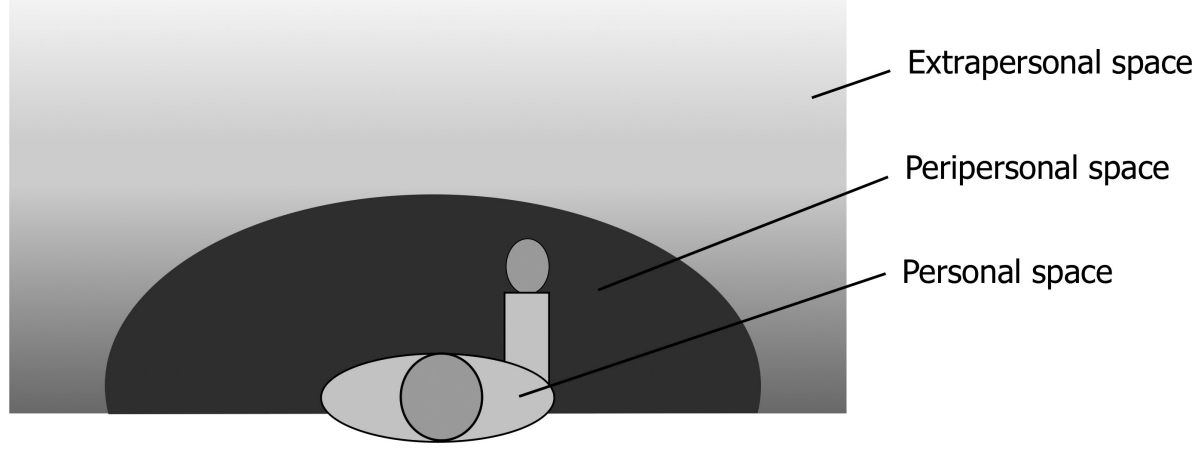

Figure 2. Space can be divided into personal space, peripersonal space, and extrapersonal space. A patient's space can be divided into personal space, peripersonal space, and extrapersonal space. USN patients are often associated with neglect symptoms in any of the three spaces, but they may occur in peripersonal space and not in extrapersonal space, or vice versa. 


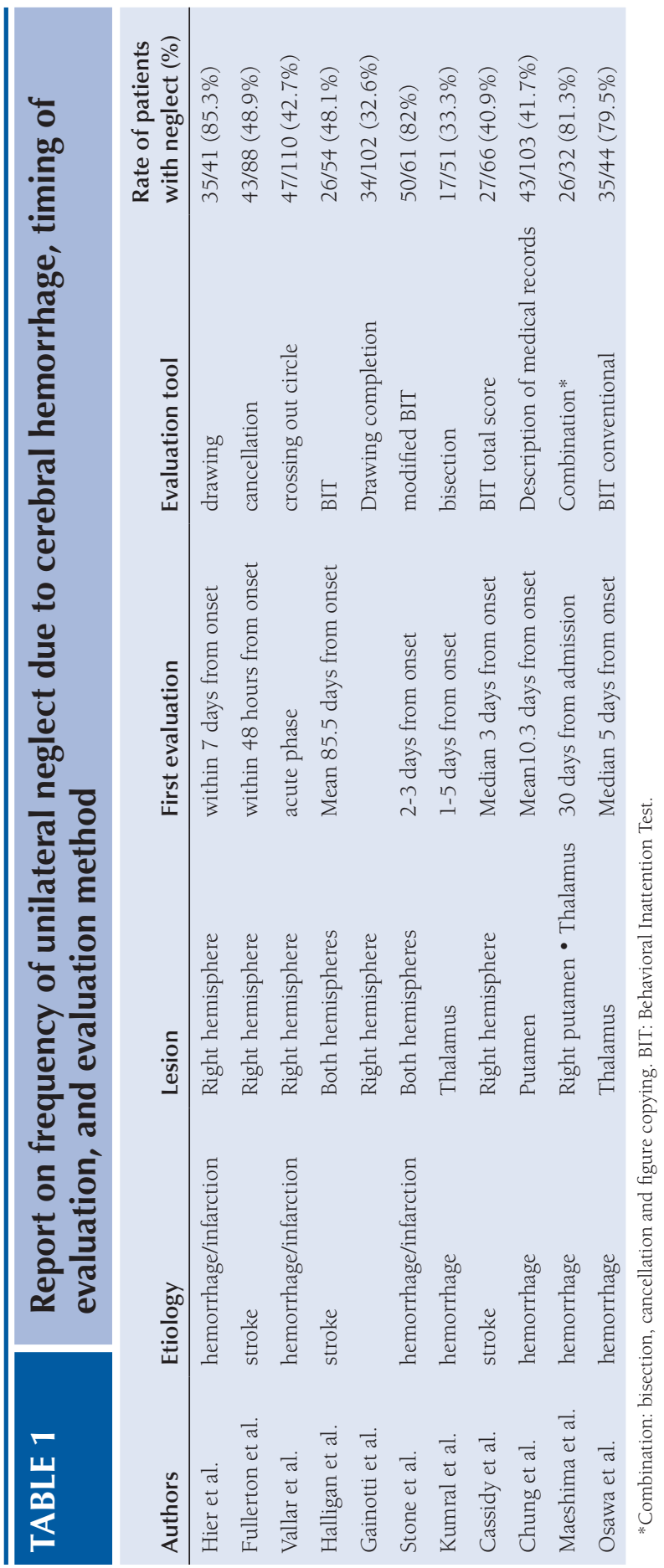


providing descriptions of photographic scenes, reading sentences, and drawing are also used in the evaluation (Figure 3). Multiple tests should be combined to avoid overlooking some symptoms (16). The standardized BIT behavioral neglect test is often used $(7,10,13,15)$. It consists of six typical tests and nine behavioral tests, including the line cancellation test, letter cancellation test, star cancellation test, figure copying, line bisection test, and drawing test (17). In a typical test, the total score is 146 points and the cut-off score is below 129 points. Compared to the drawing and bisection tests, the score of the cancellation test carries significant weight, making it easier to identify recovery of the acute phase. However, even cases that are not apparent from typical testing are often associated with symptoms of neglect in daily living. Therefore, a typical test would have individual cut-off values for six sub-tests, and if any of them falls below the cut-off value, a behavioral test is recommended.

In addition, USN is not only apparent by the desk evaluation, but also causes various problems in daily living. Specifically, there are abnormal behaviors such as not noticing a voice arising from one side of the patient, leaving food on one side of the plate, leaving one side of the beard unshaven, falls due to unregistered paralysis or impaired sensation of the hand or foot on one side of the body, forgetting to apply the brakes in a left-handed wheelchair, and hitting obstacles on one side. Halligan et al. (18) created an 11-item checklist to report daily behavior abnormalities. The Catherine Bergego Scale has been used in recent years to

\section{Drawing}

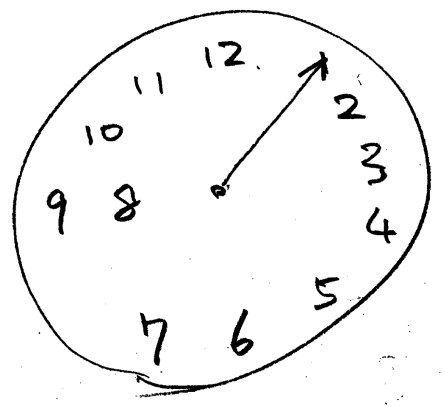

a clock

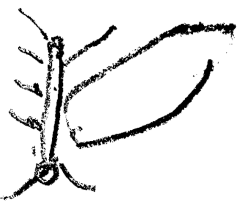

a butterfly

\section{Copy a picture of a flower}
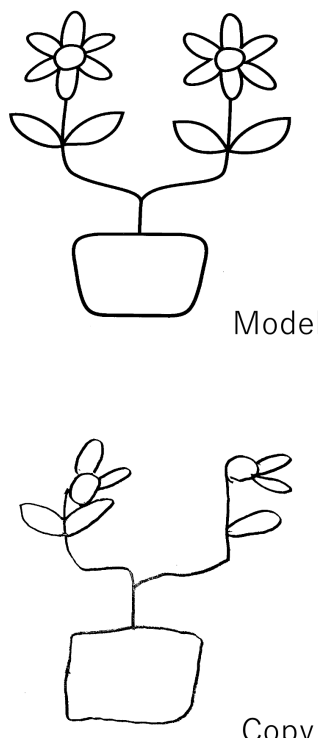

Figure 3. Patients with unilateral spatial neglect were unaware of the left side in drawing and copying. Examples of errors and omissions in left-sided features due to unilateral spatial neglect in drawing and copying tasks performed on patients due to stroke. 
quantify USN in daily living $(19,20)$. This is an evaluation method formed from 10 items such as use of cosmetics, dressing, and eating, and consists of observation evaluation and self-evaluation. Evaluating actual living conditions is also important for understanding the clinical condition and formulating treatment approaches.

\section{ANATOMICAL BASIS OF SPATIAL ATTENTION AND LESIONS CAUSING UNILATERAL SPATIAL NEGLECT}

USN is thought to be due to lesions of the parieto-occipital junction of the right cerebral hemisphere, but also lesions limited to the frontal lobe, cerebral infarction in the posterior cerebral artery region, and cerebral infarction in the anterior choroidal artery region. In addition, USN is frequently caused by putaminal hemorrhage and thalamic hemorrhage. There are also reports of USN being caused by left cerebral hemisphere lesions. Recently, the roles of the mid-superior temporal gyrus and the dorsolateral frontal cortex have also been highlighted $(21,22)$. Mesulam (23), who focused on the diversity of such lesions and the impaired functions in USN, proposed a neural network hypothesis of spatial attention consisting of the parietal lobe, frontal lobe, cingulate gyrus and subcortical thalamus, corpus striatum, and superior colliculi. Spatial attention consists of sensory and motor elements. The inferior parietal lobule is responsible for the sensory element while the posterior region from the inferior frontal gyrus to the middle frontal gyrus is responsible for the motor element. The role of lesions in these cortical regions has been emphasized; however, in recent times, network dysfunction due to lesions present in the neural pathway of the white matter has also been considered important. In particular, there are three fibers in the superior longitudinal fascicle that connect the frontal and parietal lobes. Moreover, the dorsal attention network is engaged in externally directed attention and the ventral attention network is responsible for passive attention (24). Injury to the right ventral attention network reduces the functional coupling of the dorsal attention network on the same side and increases the functional coupling of the dorsal attention network on the contralateral side, resulting in an imbalance of attention between the left and right hemispheres and the eventual emergence of USN (25).

USN due to stroke may improve or disappear during rehabilitation, but often remains. Hier et al. (12) found that approximately 85\% of cases of right hemisphere injury within a week of onset developed USN, and in the transient cases, the median recovery period was 9 weeks. On the other hand, only 13\% of the USN was present at 2-4 weeks of onset and disappeared completely after 6 months (26).

Particularly in cerebral hemorrhage, the bleeding site, level of hematoma, and age are closely related to the prognosis of USN. This symptom has been reported to be common with bleeding of more than $30 \mathrm{~mL}$ (14). However, there have been patients in whom USN disappeared even when the hematoma exceeded $50 \mathrm{~mL}$, and all were under 50 years of age. In other words, the prognosis of USN due to putaminal hemorrhage can vary greatly depending on age (14). Lesions restricted to the thalamus trigger USN at a high rate in the acute phase even when the hematoma level is low (15), but are often transient, eventually disappearing (14). 

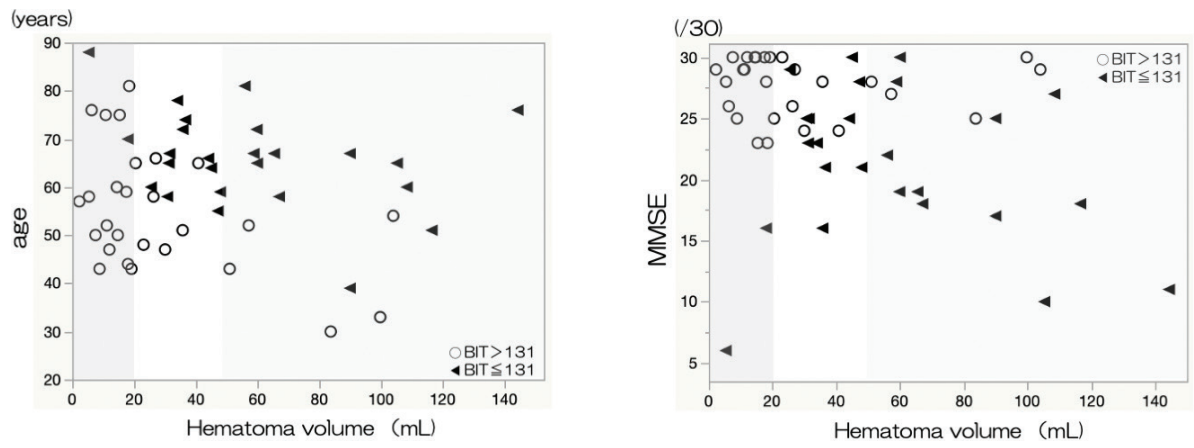

Figure 4. The relationship between hematoma levels in patients with right putaminal hemorrhage who were admitted for rehabilitation and underwent regular BIT testing. Unilateral spatial neglect, which was seen in putaminal hemorrhage, was milder in younger patients and associated with better residual cognitive function even with the same level of hematoma.

Figure 4 shows the relationship between hematoma levels in patients with right putaminal hemorrhage undergoing rehabilitation in the subacute phase and regular BIT testing. Unilateral spatial neglect, which was seen in putaminal hemorrhage, was milder in younger patients and associated with better residual cognitive function even with the same level of hematoma.

\section{MECHANISM OF UNILATERAL SPATIAL NEGLECT}

Many hypotheses have been proposed regarding the mechanism of onset of USN. Some posit that: (i) elemental disorders such as visual field disorders and ocular motor disorders are causal factors (27); (ii) spatial representation disorder (28) impairs the psychological representation of the outside world; (iii) caution imbalance impairs the direction of caution towards the opposite side to a damaged hemisphere (29); (iv) attention and arousal level is decreased due to the impairment of networks such as the cortex and limbic system, and reticular formation in the thalamus and midbrain of the temporoparietal occipital lobe and frontal lobe (30); (v) USN is a directional attention disorder (23); and (vi) there is a subjective coordinate shift of the trunk (31). However, it is difficult to explain the onset of USN using only a single mechanism. Therefore, treatment strategies should be formulated only after examining the characteristics of the symptoms and determining which onset mechanism most likely applies to the patient's symptoms.

\section{REHABILITATION FOR UNILATERAL SPATIAL NEGLECT}

Rehabilitation for USN is broadly classified as a 'top-down mechanism' that encourages attention to the neglected side and changes in behavior, and a 
'bottom-up mechanism' that activates higher-order central nerves due to stimulation from the periphery $(32,33)$. Training methods using the top-down mechanism include sustained attention training (34) using auditory feedback and visual scanning $(35,36)$. With these methods, the patient needs to be personally aware of the neglect symptoms and actively pay attention to them. For cases where the patient has other higher-order brain dysfunctions, training may be difficult. In contrast, training methods using the bottom-up mechanism include electrical stimulation (37), caloric stimulation $(38,39)$, and visual stimulation (40). These include hemi-visual field or monocular shielding $(41,42)$, and rotation of the trunk (43). Although these methods have been effective temporally and spatially, no large-scale randomized trials have been conducted (44), and there are few reports based on empirical evidence.

In addition, functional approaches have been taken to improve patient independence by repeatedly practicing important ADL (45); although, since they do not encourage improvement of universal spatial neglect per se, generalization to ADL is difficult. However, there is little evidence that even the top-down and bottom-up approaches can be generalized to ADL. A functional approach that can be easily linked with daily living and specific results that are easily understood would be a useful rehabilitation tool. In a cohort of early onset left USN patients with severe left hemiplegia, Osawa et al. (46) compared a group that performed a family participation type of self-training (family participation group) and a group that underwent training without family participation (family non-participation group) for approximately 3 weeks. They reported an improvement in BIT score in the former group only, but also improvement of the Barthel Index and transfer/ mobility capability, which are indices of ADL. In addition to training targeting only USN, training that improves general cognitive and attention function may be useful for improving disorders caused by USN.

When a USN patient is discharged, further support is needed including creating an environment such that ADL impairment due to neglect symptoms is reduced to the minimum, giving the family an adequate explanation of the symptoms prior to discharge, and maximizing the use of social systems (physical disability handbooks and long-term care insurance). Experiencing USN does not necessarily mean that one should give up on returning to work. The reason being, that if adjustments in the home and workplace environments are successful, there is every possibility of returning to work. Rehabilitation professionals, such as doctors, nurses, physiotherapists, occupational therapists, speech therapists, dieticians, and social workers, must respond appropriately.

\section{CONCLUSION}

In stroke patients, USN is one of the factors that inhibit ADL and social rehabilitation. In order to detect USN, tests are usually carried out at the desk, but it is also important to identify wider problems by observing ADL. There are various reports on the treatment of unilateral neglect patients. However, rather than simply paying attention to the neglected side, the symptom characteristics need to be understood and the rehabilitation team needs to provide appropriate guidance. 
Conflict of interest: The authors declare no potential conflict of interest with respect to research, authorship and/or publication of this chapter.

Copyright and Permission Statement: The authors confirm that the materials included in this chapter do not violate copyright laws. Where relevant, appropriate permissions have been obtained from the original copyright holder(s), and all original sources have been appropriately acknowledged or referenced.

\section{REFERENCES}

1. Heilman KM. Neglect and related disorders. Heilman KM, Valenstein E (eds): Clinical Neuropsychology, 3rd ed. New York, USA: Oxford University Press; 1993. p. 279-336.

2. Halligan PW. Hemianopia and visual neglect: a question of balance? J Neurol Neurosurg Psychiatry. 1999;67:565-6. https://doi.org/10.1136/jnnp.67.5.565

3. Buxbaum LJ, Ferraro MK, Veramonti T, Farne A, Whyte J, Ladavas E, et al. Hemispatial neglect: Subtypes, neuroamatomy, and disability. Neurology. 2004;9:749-56. https://doi.org/10.1212/01. WNL.0000113730.73031.F4

4. Hillis AE, Newhart M, Heidler J, Barker PB, Herskovits EH, Degaonkar M. Anatomy of spatial attention: insights from perfusion imaging and hemispatial neglect in acute stroke. J Neurosci. 2005;251:3161-7. https://doi.org/10.1523/JNEUROSCI.4468-04.2005

5. Fullerton KJ, McSherry D, Stout RW. Albert's test: a neglected test of perceptual neglect. Lancet. 1986;22;1(8478):430-2. https://doi.org/10.1016/S0140-6736(86)92381-0

6. Vallar G, Perani D. The anatomy of unilateral neglect after right-hemisphere stroke lesions. A clinical/CT-scan correlation study in man. Neuropsychologia. 1986;24:609-22. https://doi. org/10.1016/0028-3932(86)90001-1

7. Halligan PW, Marshall JC, Wade DT. Visuospatial neglect: Underlying factors and test sensitivity. Lancet. 1989;334(8668):908-11. https://doi.org/10.1016/S0140-6736(89)91561-4

8. Gainotti G, Giusttolisi L, Nocentini U. Contralateral and ipsilateral disorders of visual attention in patients with unilateral brain damage. J Neurol Neurosurg Psychiatry. 1990;53:422-6. https://doi. org/10.1136/jnnp.53.5.422

9. Kumral E, Kocaer T, Ertübey NO, Kumral K. Thalamic hemorrhage. A prospective study of 100 patients. Stroke. 1995;26:964-70. https://doi.org/10.1161/01.STR.26.6.964

10. Cassidy TP, Lewis S, Gray CS. Recovery from visuospatial neglect in stroke patients. J Neurol Neurosurg Psychiatry. 1998;64(4):555-7. https://doi.org/10.1136/jnnp.64.4.555

11. Chung CS, Caplan LR, Yamamoto Y, Chang HM, Lee S-J, Song H-J, et al. Striatocapsular haemorrhage. Brain. 2000;123:1850-62. https://doi.org/10.1093/brain/123.9.1850

12. Hier DB, Mondlock J, Caplan LR. Behavioral abnormalities after right hemisphere stroke. Neurology. 1983;33:337-44. https://doi.org/10.1212/WNL.33.3.337

13. Stone SP, Patel P, Greenwood RJ, Halligan PW. Measuring visual neglect in acute stroke and predicting its recovery: the visual neglect recovery index. J Neurol Neurosurg Psychiat. 1992;55:431-6. https:// doi.org/10.1136/jnnp.55.6.431

14. Maeshima S, Ueyoshi A, Matsumoto T, Boh-oka SI, Yoshida M, Itakura T, et al. Unilateral spatial neglect in patients with cerebral hemorrhage: The relationship between hematoma volume and prognosis. J Clin Neurosci. 2002;9:544-8. https://doi.org/10.1054/jocn.2002.1135

15. Osawa A, Maeshima S. Aphasia and unilateral spatial neglect due to acute thalamic hemorrhage: clinical correlations and outcomes. Neurol Sci. 2016;37:565-72. https://doi.org/10.1007/ s10072-016-2476-2

16. Maeshima S, Truman G, Smith DS, Dohi N, Shigeno K, Itakura T, et al. Factor analysis of the components of 12 standard test batteries, for unilateral spatial neglect, reveals that they contain a number of discrete and important clinical variables. Brain Inj. 2001;15:125-37. https://doi. org/10.1080/026990501458362 
17. Wilson BA, Cockburn J, Halligan PW. Behavioral Inattention Test (BIT). London, UK: Thames Valley Test Company; 1987.

18. Halligan PW, Cockburn J, Wilson BA. The behavioural assessment of visual neglect. Neuropsychol Rehabil. 1991;1:5-32. https://doi.org/10.1080/09602019108401377

19. Azouvi P, Olivier S, De Montety G, Samuel C, Louis-Dreyfus A, Tesio L. Behavioral assessment of unilateral neglect: study of the psychometric properties of the Catherine Bergego Scale. Arch Phys Med Rehabil. 2003;84(1):51-7. https://doi.org/10.1053/apmr.2003.50062

20. Azouvi P. Functional consequences and awareness of unilateral neglect: study of an evaluation scale. Neuropsychol Rehabil. 1996;6:133-50. https://doi.org/10.1080/713755501

21. Karnath H, Ferber S, Himmelbach M. Spatial awareness is a function of the temporal not the posterior parietal lobe. Nature. 2001;411:950-953. https://doi.org/10.1038/35082075

22. Mort D, Malhotra P, Mannan SK, Rorden C, Pambakian A, Kennard C, et al. The anatomy of visual neglect. Brain. 2003;126:1986-97. https://doi.org/10.1093/brain/awg200

23. Mesulam M-M. A cortical network for directed attention and unilateral neglect. Ann Neurol. 1981;10 : 309-25. https://doi.org/10.1002/ana.410100402

24. Corbetta M, Shulman GL. Control of goal-directed and stimulus-driven attention in the brain. Nat Rev Neurosci. 2002;3(3):201-15. https://doi.org/10.1038/nrn755

25. Corbetta M, Shulman GL. Spatial neglect and attention networks. Ann Rev Neuroscience. 2011;34:569-99. https://doi.org/10.1146/annurev-neuro-061010-113731

26. Appelros P, Nydevik I, Karlsson GM, Thorwalls A, Seiger Å. Recovery from unilateral neglect after right-hemisphere stroke. Disabil Rehabil. 2004;26:471-7. https://doi.org/10.1080/09638280410001 663058

27. Paterson A, Zangwill OL. Disorders of visual space perception associated with lesions of the right cerebral hemisphere. Brain. 1944;67:331-58. https://doi.org/10.1093/brain/67.4.331

28. Bisiach E, Luzzatti C. Unilateral neglect of representational space. Cortex. 1978;14:129-33. https:// doi.org/10.1016/S0010-9452(78)80016-1

29. Kinsbourne M. Hemineglect and hemisphere rivalry. Adv Neurol. 1977;18: 41-9.

30. Heilman KM, Valenstein E. Mechanisms underlying hemispatial neglect. Ann Neurol. 1979;5:166-70. https://doi.org/10.1002/ana.410050210

31. Driver J, Mattingley JB. Partial neglect and visual awareness. Nat. Neurosci. 1998;1:17-22. https:// doi.org/10.1038/217

32. Rode G, Pisella L, Rossetti Y, Farnè A, Boisson D. Bottom-up transfer of sensory-motor plasticity to recovery of spatial cognition: visuomotor adaptation and spatial neglect. Brain Res. 2003;142: 273-87. https://doi.org/10.1016/S0079-6123(03)42019-0

33. Frassinetti F, Angeli V, Meneghello F, Avanzi S, Làdavas E. Long-lasting amelioration of visuospatial neglect by prism adaptation. Brain. 2002;125:608-23. https://doi.org/10.1093/brain/awf056

34. Robertson IH, Tegner R, Tham K, Lo A, Nimmo-Smith I. Sustained attention training for unilateral neglect: theoretical and rehabilitation implications. J Clin Exp Neuropsychol. 1995;17(3):416-30. https://doi.org/10.1080/01688639508405133

35. Weinberg J, Diller L, Gordon WA, Gerstman LJ, Lieberman A, Lakin P, et al. Visual scanning training effect on reading-related tasks in acquired right brain damage. Arch Phys Med Rehabil. 1977;58:479-86.

36. Antonucci G, Guariglia C, Judica A, Magnotti L, Paolucci S, Pizzamiglio L, et al. Effectiveness of neglect rehabilitation in a randomized group study. J Clin Exp Neuropsychol. 1995;17:383-9. https:// doi.org/10.1080/01688639508405131

37. Valler G, Rusconi ML, Barozzi SBBOD, Bernardini B, Ovadia D, Papagno C, et al. Improvement of left visuo-spatial hemineglect by left-sided transcutaneous electrical stimulation. Neuropsychologia. 1995;33:73-82. https://doi.org/10.1016/0028-3932(94)00088-7

38. Rubens AB. Caloric stimulation and unilateral visual neglect. Neurology. 1985;35:1019-24. https:// doi.org/10.1212/WNL.35.7.1019

39. Cappa S, Sterzi R, Vallar G, Bisiach E. Remission of hemineglect and anosognosia during vestibular stimulation. Neuropsychol Rehabil. 2001;11:17-31. 
40. Pizzamiglio L, Frasca R, Guarigkia C, Incoccia C, Antonucci G. Effect of optokinetic stimulation in patients with visual neglect. Cortex. 1990;26:535-40. https://doi.org/10.1016/S0010-9452(13)80303-6

41. Arai T, Ohi H, Sasaki H, Nobuto H, Tanaka K. Hemispatial sunglass : effect on unilateral spatial neglect. Arch Phys Med Rehabil. 1997;78:230-2. https://doi.org/10.1016/S0003-9993(97)90269-0

42. Beis JM, André JM, Baumgarten A, Challier B. Eye patching in unilateral spatial neglect : efficacy of two methods. Arch Phys Med Rehabil. 1999;80:71-6. https://doi.org/10.1016/S0003-9993(99)90310-6

43. Wiart L, Saint Côme AB, Debelleix X, Petit H, Joseph PA, Mazaux JM, et al. Unilateral neglect syndrome rehabilitation by trunk rotation and scanning training. Arch Phys Med Rehabil. 1997;78:424-9. https://doi.org/10.1016/S0003-9993(97)90236-7

44. Bowen A, Lincoln NB, Dewey ME. Spatial neglect: Is Rehabilitation Effective? Stroke 2002;33: 2728-9. https://doi.org/10.1161/01.STR.0000035747.03607.1A

45. Edmans JA, Webster J, Lincoln NB. A comparison of two approaches in the treatment of perceptual problems after stroke. Clin Rehabil 2000;14:230-43. https://doi.org/10.1191/026921500673333145

46. Osawa A, Maeshima S. Family participation can improve unilateral spatial neglect in patients with acute right hemispheric stroke. Eur Neurol. 2010;63(3):170-5. https://doi.org/10.1159/000286517 
